\title{
THE PREVALENCE OF SOMATIC SYMPTOM DISORDERS AMONG REGULAR FEMALE PATIENTS OF FAITH HEALERS
}

\author{
Zaufishan Qureshi ${ }^{1}$ Anum Shahzad ${ }^{2}$ \& Sehrish Naeem ${ }^{3}$ \\ 1. Department of Psychology, Foundation University Islamabad \\ 2. Department of Psychology, Fatima Jinnah Women University, Rawalpindi \\ 3. Department of Psychology, University of Poonch, Rawalakot \\ Corresponding author: zaofishan.qureshi@gmail.com
}

ABSTARCT: The study aimed to study the prevalence of Somatic symptom and related disorders among regular female patients of faith healers. The study was exploratory in nature and case studies of ten females were taken. The study aimed to investigate the prevalence of Somatic symptom and related disorders among those women who regularly visit Faith healers for the cure of all major to minor illnesses and do not trust doctors after nil diagnosis. The cases were taken from Rawalakot and Rawalpindi. Detailed histories and current condition of the patients were obtained. The patients were asked for their symptoms, incidence and onset of symptoms, severity and intensity of symptoms and recurrence. On the basis of which, the patients were diagnosed according to DSM-V (2013) criteria for Somatic symptom and related disorders cluster. The results showed that 7 out 10 women were suffering from some type of somatic symptom and related disorders. The patients needed to seek psychological help but they weren't aware of this fact. All of the patients turned to faith healers because doctors provided nil diagnosis as their bodily symptoms were purely psychological.

KEYWORDS: Somatic Symptoms Disorder, faith healers, DSM-V

\section{INTRODUCTION}

Psycho-somatic disorders are those which involve bodily complaints due to psychological reasons. Medical checkup mostly result in nil diagnosis because no evidence of the bodily symptom can be found. The history of such bodily complaints with no medical evidence has been a subject of interest for both Psychiatrists and Psychologists. It is important that both communities work on the study and investigation of this disorder as it concerns both communities. Somatoform disorders are referred as somatic symptom and related disorders in the recent edition of the diagnostic and statistical manual of mental disorders (DSM, V, 2013). Such a disorder tends to be long lasting and chronic. It includes physical complaints that can last up to a couple of years causing substantial impairment in social life as well as daily routines of the individual. There might or might not be medical explanations for the symptoms such individuals experience. DSM-IV excluded organically explainable comorbidities for instance cancer and cardiovascular diseases in the patients. However, such conditions can be a part of SSD diagnosis now, increasing the chances of suitable and correct treatment. As per DSM- V, somatic symptoms include factitious disorder, conversion disorder, psychological factors effecting other medical conditions, illness anxiety disorders, other specified somatic symptom and related disorder, and unspecified somatic symptom and related disorder. The term somatization is defined in ICD-10 as numerous, physical symptoms which are regularly varying as well as recurring and are present for a minimum of two years before the individual can be referred to a psychiatrist. For patients who had physical symptoms and visited medical help recurrently regardless of negative investigations, the term of unexplained somatic complaints was presented. It is very much likely for such patients to be the victims of stigmatization and disregarded by their general physicians or medical doctors; they can be labeled as having problems which are not real or are all in their heads. Nevertheless, with the increase in research in this area and the link between brain, immunity and other biological systems, it is becoming clear that SSD is not merely a condition that patients make up and have control over, thereby the symptoms should be considered unfeigned instead of malingering.

Healing may be physical or psychological and not without the mutual reception of these two dimensions of human health. In psychiatry and psychology, healing is the process by which neuroses and psychoses are resolved to the degree that the client is able to lead a normal and healthy life and a fulfilling existence in the world. Religious and spiritual beliefs and practices are important in the lives of many patients, yet medical students, residents and physicians are often uncertain about whether, when, or how, to address spiritual or religious issues. Faith based healing is an umbrella term for a family of treatment methods which are based upon mysticism or claimed revelations, rather than the empirical evidence which is the foundation of scientific medicine. Many, though not all, faith healing methods implicitly assume some form of substance dualism, based upon the hypothesis that physical symptoms of illness are a manifestation of disturbances in some nonphysical component of the person. The language used to describe this spiritual substance varies, but common examples are spirit, soul, chakra, or human energy field. Despite this, faith healing traditions are also known to occur in cultures in which some form of monism is dominant, such as certain schools of Hinduism. Some faith based healing methods invoke the intervention of a nonhuman supernatural being or beings, supposedly to heal the patient on behalf of the practitioner. These methods remain controversial, both as a result of innate conceptual difficulties (for instance, many philosophers question how a nonphysical agent could interact with a physical body), as well as the lack of reproducible, scientifically documented evidence for the efficacy of any of these healing methods (Vyse, 2000; Egnew, 2005). People from non-western and non- Christian context may also have a belief that there mental distress, anxious mood and other forms of psychological pathology can be better cope through religious and spirituality practices including (offering prayers, meditation, wearing taweez \& talismans etc. (Watson-Franke, 1977 ; Helming, 2011). A research conducted in India depicts that Indians were more likely to prefer different strategies of spiritual 
practices in order to alleviate distress, including 'indigenous forms of medicine and healing, homeopathic medicines, yoga, and the exorcism of evil spirits (Laungani, 1994). PEW Research Centre conducted survey on world Muslims namely Nine countries were included, after the results it was conclude that: peoples have different views related to supernatural forces like, amulet, magic or sorcery, witchcraft, demons \& devil and the evil eye (PEW, 2012). Objectives of the Study:

To investigate the prevalence of Somatic symptom and related disorders among regular female patients of faith healers

Research Question:

What is the prevalence of Somatic symptom and related disorders in regular female patients of faith healers?

\section{METHOD:}

The proposed study intended to find out the prevalence of Somatic symptom disorders among regular female patients of faith healers. The study followed a "survey" research design. Both "faith healing" and "possible somatic symptom and related disorders" are perceived as dependent variables.

Participants:

Convenient sampling technique and snowball sampling technique was used to select the respondents of the study. The researcher included 10 female cases from Rawalpindi and Rawalakot. Instruments:

A specific interview schedule was developed for the proposed study which would address the research questions in detail.

DSM-V (2013) was used as a valid and reliable measure and diagnostic tool for Somatic symptom disorder.

Procedure:

The researcher organized meetings with the prospective respondents. They visited easily approachable cities and villages of Punjab and Kashmir. The researcher gathered the data after building a satisfactory level of rapport with the respondents. The issues of confidentiality and compliance to the ethical standards were given proper consideration.

Data Analysis:

The analysis of the interview schedules was carried by using DSMV (diagnostic \& Statistical manual for mental disorders). Percentages were computed.

\section{RESULT:}

7 out of 10 females had proneness to somatic symptom and related disorders. The prevalence of somatic symptom and related disorders was $70 \%$. Conversion disorder proneness was most prevalent (4 out of 10).

\section{DISCUSSION}

The current study involved 10 case studies of those women who regularly visit faith healers for their bodily complaints. The findings are discussed as follows:

\section{Commonly prevalent symptoms}

The symptoms for which the subjects sorted faith based healing included Sleeplessness, Anxiousness about one's illness, Nightmares, Irritability, Restlessness, Depressed mood, No sexual arousal, Lack of interest in occupational and pleasurable activities, Suspicious attitude towards others, Headache, Anxious feelings, Dissatisfaction, Over eating, Poor appetite, Auditory hallucinations, Aggressive behavior, Delusions (including persecutory and somatic), Body pain , Loneliness, Hearing disturbance, Weeping and Insomnia .

The prevalent disorders were Conversion disorder, somatic symptom disorder, and illness anxiety disorders, which were diagnosed in the respondents (by applying the criteria of DSM V) after interviews and analyzing their symptoms.

Patients diagnosed with conversion disorder experienced sensory and motor problems along with somatic complaints. These cases also involved many psycho-social and economic stressors such as, marital problems, poverty, migration to another city, and loneliness. The complaints included a non-stop shaky arm, sensation and throbbing in ears, twitching of foot finger, and sensation of termites crawling over body. The symptoms were experienced for more than 6 months. Medical diagnosis was nil.

Patients with somatic symptom disorder involved severe pain in variety of body parts that lasted for more than 6 months. They also experienced psycho-social, psycho-sexual and financial issues. One of the cases was going through a pending divorce case. Another was dissatisfied sexually from husband since the first day of marriage and also faced domestic violence and marital rape. Pain was severe and genuine but no medical evidence was there and diagnosis was nil. Illness anxiety disorder was also prevalent. Patient was constantly worried about the bodily symptoms and constantly wept and feared her pain and condition. It impaired her married life, interpersonal relationships and daily functioning. The symptoms were experienced for more than six months.

\section{CONCLUSION:}

The study concludes that awareness about somatic symptom and related disorders should be given by general physicians so that people seek psychological help rather than faith based healing methods that have not only high rate of recurrence but also aren't genuine in most of the cases. The study investigated the prevalence

\begin{tabular}{|c|c|c|c|c|c|c|c|c|c|c|}
\hline $\begin{array}{l}\text { Somatic } \\
\text { symptom and } \\
\text { related Disorders }\end{array}$ & Case 1 & Case 2 & Case 3 & Case 4 & Case 5 & Case 6 & Case 7 & Case 8 & Case 9 & Percentages \\
\hline $\begin{array}{l}\text { Conversion } \\
\text { Disorder }\end{array}$ & 1 & 1 & 1 & & 1 & & & & & $40 \%$ \\
\hline $\begin{array}{l}\text { Somatic } \\
\text { Symptoms } \\
\text { Disorder }\end{array}$ & & & & 1 & & & 1 & & & $20 \%$ \\
\hline
\end{tabular}

Table 1: Shows percentages of somatic symptoms and related disorders among cases. 
of only one cluster of disorders among so many mental disorders and yet it found that 7 out of 10 female cases (70\%) were suffering from somatic symptom and related disorders. It is dreading to imagine how many others could be diagnosed with other sort of disorders that need psychological and medical help.

\section{REFERENCES:}

- American Psychiatric Association. (2013). Diagnostic and statistical manual of mental disorders (5th Ed.). Washington, DC.

- Helming MB. (2011) healing though prayer: A qualitative study. Holistic Nursing Practice, 25(1):33-44.

- Laungani, E. 1994. Cultural differences in stress: India and England. Counseling Psychology Review 9(4): 25-37.
- Thomas R. Egnew (2005) the meaning of healing: transcending suffering. Annals of family medicine. 3(3): 255-262.

- Vyse, Stuart A (2000). Believing in Magic: The Psychology of Superstition. Oxford, England: Oxford University Press. pp. 19-22.

- Watson, L. C. and Watson-Franke, M.-b. (1977), Spirits, Dreams, and the Resolution of Conflict among Urban Guajiro Women. Ethos, 5: 388-408.

- World Health Organization. (1992). ICD-10 Classifications of Mental and Behavioral Disorder: Clinical Descriptions and Diagnostic Guidelines. Geneva. World Health Organization.

Page $\mid 11$ 